\title{
Arts and Scholastic Performance
}

\author{
Arnaud Cabanac \\ De Rochebelle, C.S.D.D, Québec, Canada \\ Email: Arnaud.cabanac@csdecou.qc.ca
}

How to cite this paper: Cabanac, A. (2017). Arts and Scholastic Performance. Creative Education, 8, 2393-2399. https://doi.org/10.4236/ce.2017.815163

Received: October 17, 2017

Accepted: December 4, 2017

Published: December 7, 2017

Copyright $\odot 2017$ by author and Scientific Research Publishing Inc. This work is licensed under the Creative Commons Attribution International License (CC BY 4.0).

http://creativecommons.org/licenses/by/4.0/

\begin{abstract}
Pleasant environmental music during an academic test helped students to overcome stress. As a result the grades they obtained were higher. It was also demonstrated that students selecting music as optional course performed better, than music-less control students over three consecutive years. Yet, there remained ambiguities as for the causes of the higher test performance of these students. Our study confirmed a Mozart effect, and further showed a latency of two to three years for such a positive influence to take place, suggesting that it is the practice of music itself that helps cognition. We showed also that other art courses, when freely chosen, have similar positive influences on students' performances, illustrating that the principles of learning are linked to hedonism and to will effort in a more general manner.
\end{abstract}

\section{Keywords}

Music "Mozart Effect", Arts Academic Achievement, Education Pleasure Will Effort

\section{Introduction}

Ambient music in the examination room has been demonstrated to have a positive influence on students while performing academic tests as it helped them to overcome stress, to devote more time to stressful and more complicated tasks and their eventual grades were higher as demonstrated (Perlovsky, Cabanac, Bonniot-Cabanac, \& Cabanac, 2013). It has also been shown that students selecting musical courses during their academics performed better than control music-less students (Gouzouasis, Guhn, \& Kishor, 2007; Cabanac, Perlovsky, Bonniot-Cabanac, \& Cabanac, 2013). Yet, there remained ambiguities as for the causes of the higher test performance of these students. Music has been shown to develop IQ but personality and individual differences were recently suggested to play an important part in the efforts children would put to reach success (Corri- 
gall, Schellenberg, \& Misura, 2013). In this present study, we asked whether freely chosen, would other kinds of art courses also have such positive influence as music had on academic performance? And also, how long would the delay be before any music positive influence to take place in teenagers?

\section{Methods}

The population studied consisted of students from a secondary school of the province of Quebec in Canada. De Rochebelle secondary school is a large school consisting of many buildings connected together with about 1700 students. The students of the present study belonged to the International Baccalaureate program for which they were selected on their high grades in previous years. They formed a homogenous group in terms of their grades. At registration, all students were requested to choose the kind of art they were going to follow on their next year. The options were Plastic art, Theater, and Music. A forth option which was sport (basket-ball) has been removed from the samples even though they were linked with music, because those students were definitely putting too much of their efforts into sports and as such were not normally distributed as the three others groups.

The mean grade differences between groups after 2, 5, and 10 months over the three years of the study were computed. Winter and summer holidays were discarded as school stopped, even though it is likely that the student were practicing their art at will during that time.

We compared the marks obtained by the three different groups of students: 60 Plastic arts students, 60 Theater students, and 30 - 40 Music students, for a grand total of 160 students included into the survey. Students, were 12 - 13 years old, of both genders at the beginning of the study, and were therefore $14-15$ at the end of the study.

In the three different courses of arts (Plastic art, Theater, and Music), students were asked similar tasks, including creation, interpretation, and appreciation of the art.

In the Music course, the students were evaluated on their ability to create and to play some tunes, and on their appreciation of different musical compositions. Over the first semester, the teacher showed to recognize the characteristics of sound and the language that goes together, they made some dictations of melodies and of rhythms. The students learned the solfeggio, the basal rhythms, to classify the instruments by their kinds, and how to build a harmonium. Over the second semester, solfege reading was enforced, and the students were asked to play music's of different styles, they were asked to create a melody, and they were asked to listen and to analyze some music of different styles, and to understand the structure of the different kinds of music. The students had to choose a main instrument to play with, and also were asked to play two other music instruments. With an instrument of their choice the students played in a Christmas concert in front of parents and school members. Over the third semesters, those knowledge were reinforced by a composition 
and an interpretation of a short melody. Again a concert was given at the end of the school year. On the second and third year these knowledge were reinforced during the school year with a Christmas's concert and an ending of the year's concert.

In the Theater course, the students were evaluated on their ability to create and to play some dramatic works, and on their appreciation of dramatics works. Over the first semester, the students had to learn first who they were themselves in order to use it in their art. In workshops, the students were to create some short sequence dramas, and to build different characters based from different parts of their body and their voices. They also learned some history of the art of marionettes. Over the second and third semester, the students had to create some short scene with marionettes, thus learning manipulation, use of their voices, and the reading of different texts; finally, the students had to play various characters in improvised and programmed plays. On their second year they learned setting and make-up and they had to create and to play dramas and clowns. On their third year the students learned different moves and they had to write some short plays. Again on several occasions of each year the student had to perform on a stage in front of a public of schoolmates, teachers, and parents.

The Plastic arts students were evaluated on their ability to create some images with particular characteristics (personal and media), and on their abilities to appreciate some pictures. Over the three years, the students had to use different media and technics (drawing, painting, and sculpture) to create some images that were personal and some that were medias. Their teachers presented different artistic works from the patrimony in link to the current work made by the students. The students learned how to analyze and appreciate various drawings, paintings, and sculptures (their own production and well-known public ones). Most of the works were individual, but on occasions some works could be done in collaboration with a class mate. With drawings, paintings, recycling of materials, pastings, and sculptures, students became familiar with lines, dots, forms, textures, colors, melting, shades, volumes, dyeing, space organization, 3-D perspective. Here again, at the end of each year there is a big event in which the artists presented their works to the entire school and parents.

All the students were among the top grade level of their school. To judge their level on their general education, we used only results from courses with quantifiable performance including: sport, science, mathematics, ethics, geography/history, French, English, and Spanish.

\section{Results and Discussion}

Music has been demonstrated to have a positive influence on students while performing academic tests as it helped them to overcome stress, to devote more time to more stressful and more complicated tasks. As a result their grades were higher (Perlovsky, Cabanac, Bonniot-Cabanac, \& Cabanac, 2013). It has also been shown that students selecting musical courses during their academics performed better than music-less control students (Gouzouasis, Guhn, \& Kishor, 
2007; Cabanac, Perlovsky, Bonniot-Cabanac, \& Cabanac, 2013). The results from our present study confirmed previous studies. At the beginning our population was homogeneous and after only two months of practicing either Plastics arts, Theater, or Music, there were still no trend of one art having a positive influence on the academic performance in the other topics (general education). Figure 1 illustrates the homogenate results after two months of study. All groups remained homogeneous over that first year.

However, the group's grades of students following music as their artistic course began to become better than the other groups on the third year of practicing music (month-2 of that third year: Student's t-test, $p=0.04$; month-5 of the third year: Student's t-test, $p=0.19$; month-10 of the third year : Student's t-test, $p=0.07$ ), as illustrated on Figure 2. Eerola \& Eerola (2013) reported that extended music education has a positive influence on the social aspects of schooling, Kokkidou, Tsakiridou, \& Geka (2008) showed that learning a music instrument, had positive effects on school competence, academic performance, development of self-esteem and self-consciousness emotional maturity, and on the promotion of social skills. Recent theoretical hypothesis suggested that music helps resolving knowledge contradictions and, then, is fundamental for the survival of the entire human evolution (Perlovsky, 2011, 2013) study. All groups remained homogeneous over that first year.

In previous studies lay an uncertainty of whether it was due to the practice of music rather than the personal ability of the teenager that would explain the Mozart effect (Corrigall, Schellenberg, \& Misura, 2013) or the opposite phenomenon. Interestingly, the fact that it took two to three years to become significant in the present study, suggests that it is the practice of music that made the student better at school rather than a personal ability of the student. Otherwise a difference should have be present from the beginning and not been built over the years as our results showed.

Another interesting fact of the study is the analysis of Plastic art students' as they became stronger than the other students as early as the end of the first year (Student t-test, $p=0.078$ ), but confirmed thereafter on the second year (Student t-test : $p=0.043, p=0.008, p=0.009$, months-2, $-5,-10)$ and third year (Student

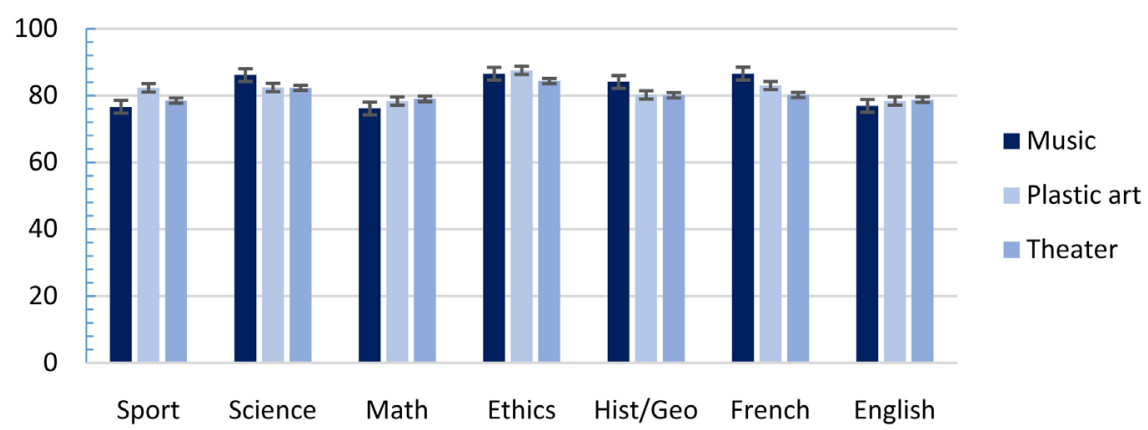

Figure 1. Mean marks from general education of 12 - 13 years old teenagers, after 2 months on the first year of study. 




Not music

Music

(a)

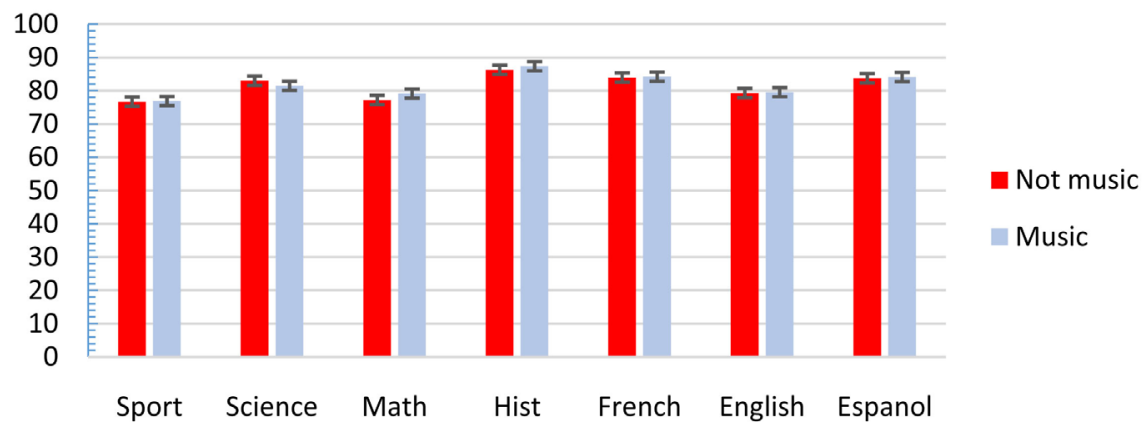

(b)

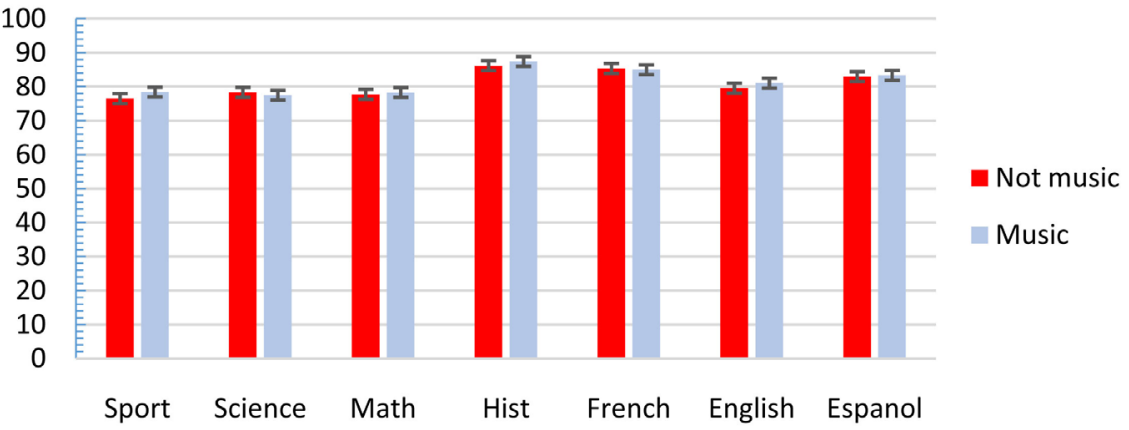

(c)

Figure 2. Mean marks of 14 - 15 teenagers after 2 ((a) $t$-test, $p=0.043)$; after 5 ((b) $t$-test: $p=0.193)$; and after 10 months $((\mathrm{c}) t$-test, $p=0.071)$ on the third year of study.

t-test: $p=0.307, p=0.059, p=0.028$, months- $2,-5,-10)$. Theater students were never better than the other art students over the three years of the study. They may have been better in some particular courses, but not as a general trend in all topics.

Further, a positive result being obtained for another art course than Music suggests a more general phenomenon. It is still unclear whether such positive result takes place only when link to Arts or if any topic when done with pleasure and effectiveness would have such an effect on scholar achievements. Further works will have to address this question specifically. The importance of emotion in decision making process has been acknowledged (Cabanac, 1992, 2002) and the importance of pleasure as the fifth influence of the universe has been proposed (Cabanac, Guillaume, Balaskó, \& Fleury, 2002; Cabanac, Cabanac, \& 
Hammel, 2011).

The influence of music and plastic art confirmed in the present results is likely to be due to the pleasure experienced by the participants. Indeed, hedonism, the experience of pleasure, is the door to cognition (Cabanac, 2010).

In the modern society lot of efforts are invested into technology. Chen, Chavez, Ong, \& Gunderson (2017) pointed out that if many educational policies provide learners with more resources (e.g., new learning activities, study materials, or technologies), less often do educators explore whether students are using these resources actually, and that making students more self-reflective about how they should approach their learning with the resources available to them the more they improve their performance.

Furthermore, will effort by itself might enhance the given motivation or/and by weakening competition with other motivations. Thus, will effort would direct the subject's attention toward those elements of choice and raise their desirability. Therefore, the choice between possible decisions becomes easier. Indeed, will effort activating emotional/hedonic memory leads a subject toward beneficial decisions (Ovsich, 2017).

We underline, in agreement with Aristote (LaCourse Munteau, 2012), the old knowledge that simple pleasure in learning should be present in a teacher's performance and satisfaction of efficiency in the student state, in order to reach a state when learning becomes a pleasure (Theron, 2009; European Commission, 2017).

\section{Conclusion}

The current paper shows relations between arts education and academic performance. Students selecting musical and plastic art courses perform better than those declining such courses, despite equally high initial achievements. This suggests that the practice of art with efficiency helps students in their academic achievements. In addition to addressing this fundamental scientific question about learning these results suggest that efforts should been made on a playful approach in education.

\section{Acknowledgements}

The author thanks De Rochebelle School (C.S.D.D., Quebec, Canada) and Director Daniel Lemelin for making available academic performance records. This research did not receive any specific grant from funding agencies in the public, commercial, or not-for-profit sectors.

\section{References}

Cabanac, A., Perlovsky, L., Bonniot-Cabanac, M. C., \& Cabanac, M. (2013). Music and Academic Performance. Behavioural Brain Research, 256, 257-260. https://doi.org/10.1016/j.bbr.2013.08.023

Cabanac, M. (1992). Pleasure: The Common Currency. Journal of Theoretical Biology, 
155, 173-200. https://doi.org/10.1016/S0022-5193(05)80594-6

Cabanac, M. (2002). What Is Emotion? Behavioural Processes, 60, 69-83. https://doi.org/10.1016/S0376-6357(02)00078-5

Cabanac, M. (2010). The Fifth Inluence. The Dialectics of Pleasure. Bloomington, IN: iUniverse, ISBN 978-1-4401-8836-7, 284 p. https://doi.org/10.13140/2.1.3610.5282

Cabanac, M., Cabanac, R., \& Hammel, H. (2011). Consciousness: The Fifth Influence. Journal of Cosmology, 14. http://journalofcosmology.com/Consciousness127.html

Cabanac, M., Guillaume, J., Balaskó, M., \& Fleury, A. (2002). Pleasure in Decision Making Situations. BMC Psychiatry, 29, 2-7. https://doi.org/10.1186/1471-244X-2-7

Chen, P., Chavez, O., Ong, D. C., \& Gunderson, B. (2017). Strategic Resource Use for Learning: A Self-Administered Intervention That Guides Self-Reflection on Effective Resource Use Enhances Academic Performance. Psychological Science, 6, 74-785. https://doi.org/10.1177/0956797617696456

Corrigall, K. A., Schellenberg, E. G., \& Misura, N. M. (2013). Music Training, Cognition, and Personality. Frontiers in Psychology, Auditory Cognitive Neuroscience, 222, 1-10. https://doi.org/10.3389/fpsyg.2013.00222

Eerola, P. S., \& Eerola, T. (2013). Extended Music Education Enhances the Quality of School Life. Journal Music Education Research, 16, 88-104.

https://doi.org/10.1080/14613808.2013.829428

European Commission (2017). Culture and Education, Press Release Data Base, Update 20 Feb. 2017. http://europa.eu/rapid/press-release_PRES-94-130_fr.htm

Gouzouasis, P., Guhn, M., \& Kishor, N. (2007). The Predictive Relationship between Achievement and Participation in Music and Achievement in Core Grade 12 Academic Subjects. Music Education Research, 9, 81-92.

https://doi.org/10.1080/14613800601127569

Kokkidou, M., Tsakiridou, E., \& Geka, M. (2008). Correlation between Music Studies and School Competence: Field Research. In M. Argyriou (Eds), Current Trends and Dynamics of School Psychology in Education and Music Pedagogy (pp.172-179). Athens: Diaplasi.

Lacourse Munteau, D. (2012). Aristote on Pleasure and Learning. In N. Seel (Eds), Encyclopedia of the Sciences of Learning (pp 312-313). Berlin : Springer.

Ovsich, A. (2017). Mathematical Models of Desire, Need, Attention, and Will Effort. In: J. Vallverdú, M. Mazzara, M. Talanov, S. Distefano, \& R. Lowe (Eds), Advanced Research on Biologically Inspired Cognitive Architerctures (Chapt-9, pp. 177-213). ISBN 9781522519478.IGI Global, USA.

Perlovsky, L. I. (2011). Music, Cognitive Function Origin and Evolution of Musical Emotions. WebmedCentral Psychology, 2, WMC001494.

Perlovsky, L. I. (2013). A Challenge to Human Evolution-Cognitive Dissonance. Frontiers in Psychology, 4, 179. https://doi.org/10.3389/fpsyg.2013.00179

Perlovsky, L., Cabanac, A., Bonniot-Cabanac, M. C., \& Cabanac, M. (2013). Mozart Effect, Cognitive Dissonance, and the Pleasure of Music. Behavioural Brain Research, 244, 9-14. https://doi.org/10.1016/j.bbr.2013.01.036

Theron, J. A. L. (2009). Learning Is a Pleasure: A Practical Guide to Successful Learning. BrookBaby Publisher. ISBN 9781626751842. 